\title{
Immunoexpression of lactoferrin in triple-negative breast cancer patients: A proposal to select a less aggressive subgroup
}

\author{
ANTONIO IENI $^{1}$, VALERIA BARRESI ${ }^{1}$, LUANA LICATA ${ }^{1}$, ROBERTA CARDIA ${ }^{1}$, CARMINE FAZZARI ${ }^{2}$, \\ GIUSEPPE NUCIFORO ${ }^{2}$, FRANCESCO CARUSO ${ }^{3}$, MICHELE CARUSO $^{4}$, \\ VINCENZO ADAMO $^{1,5}$ and GIOVANNI TUCCARI ${ }^{1}$ \\ ${ }^{1}$ Department of Human Pathology of Adult and Evolutive Age 'Gaetano Barresi', Polyclinic 'G. Martino', \\ University of Messina, I-98125 Messina; Departments of ${ }^{2}$ Pathological Anatomy, ${ }^{3}$ Oncological Surgery and ${ }^{4}$ Oncology, \\ Humanitas Catanese Center of Oncology, I-95126 Catania; ${ }^{5}$ Oncology Unit, Papardo Hospital, I-98158 Messina, Italy
}

Received October 11, 2016; Accepted January 26, 2017

DOI: $10.3892 / \mathrm{ol} .2017 .5859$

\begin{abstract}
Triple-negative breast cancer (TNBC) indicates a subset of breast carcinomas that does not express estrogen receptor (ER), progesterone receptor (PR) and human epidermal growth factor receptor-2 (HER2). According to the literature, TNBCs are aggressive tumors, characterized by a high incidence of recurrence and a high risk of disease progression. Lactoferrin (LF) is a single-chain, iron-binding glycoprotein of $\sim 700$ amino acids, which is involved in a wide range of biological activities, including iron-trafficking and carcinogenesis. The present study aimed to assess LF expression in human TNBC samples and the possible correlation with clinico-pathological parameters associated with biological aggressiveness. LF immunohistochemical expression was investigated in formalin-fixed, paraffin-embedded samples of human TNBC. Cases were analyzed according to an intensity distribution (ID) score, and only those showing an ID score of $>2$ were considered as positive for LF. LF immunostaining was encountered in $26.15 \%$ cases. A significant correlation was found between LF expression and a low Ki-67 labeling index $(\mathrm{P}=0.040)$, the absence of recurrence $(\mathrm{P}=0.010)$ and alive status $(\mathrm{P}=0.020)$. LF may assist in identifying a subset of TNBC with less aggressive biological behavior. The meaning of LF expression in TNBC remains unclear and is controversial. The present findings indicated that LF expression is correlated with a low growth fraction in these tumors. Thus, it is possible that the inhibition of the LF axis may be a valid therapeutic target for TNBC, and this should be confirmed by future studies.
\end{abstract}

Correspondence to: Dr Antonio Ieni, Department of Human Pathology of Adult and Evolutive Age 'Gaetano Barresi', Polyclinic 'G. Martino', University of Messina, Via Consolare Valeria 1, I-98125 Messina, Italy

E-mail: aieni@unime.it

Key words: breast carcinoma, triple-negative, immunohistochemistry, lactoferrin, prognosis

\section{Introduction}

Triple-negative breast cancer (TNBC) is defined as a breast carcinoma without estrogen receptor (ER) and progesterone receptor (PR) immunoexpression, and with a lack of amplification of human epidermal growth factor receptor-2 (HER2). The disease accounts for $\sim 15 \%$ of all breast carcinomas (1-3). TNBC shows biological aggressiveness and a higher recurrence rate, with no benefit from endocrine or HER2-targeted therapies (1-3). A number of studies have previously been performed to identify additional prognostic markers to better classify TNBC and stratify it into subgroups with different clinical courses (3-8).

Lactoferrin (LF), an iron binding 78- to 80-kDa glycoprotein usually present in mammalian milk, has been immunohistochemically revealed in numerous human neoplastic conditions of different sites (9-22). An immunopositive LF rate with a large variability, ranging from 7.5 to $42 \%$ of cases, has previously been identified in breast carcinoma (23-27); however, LF was more often observed in low-grade ER/PR-positive ductal carcinomas, confirming a decrease in LF immunostaining in less differentiated and more aggressive breast carcinomas (25-27). Moreover, it has been hypothesized that increased LF levels LF may be associated with reduced ER $\alpha$ and PR expression, and possibly reduced HER2 expression, and could therefore contribute to TNBC phenotype development (24). Consequently, taking into consideration the downregulation of ER, PR and HER2 at post-transcriptional levels in TNBC cell lines (24), the present study analyzed the immunohistochemical distribution of LF in a cohort of human surgical TNBC patients.

\section{Patients and methods}

Patient cohort. The present study retrospectively investigated LF immunoexpression in a cohort of 65 TNBC cases that were surgically treated by breast-conserving surgery (lumpectomy, quadrantectomy, partial mastectomy or segmental mastectomy), at the polyclinic 'G. Martino' of Messina, as well as at the Humanitas Oncology Center of Catania, between January 2001 and June 2015, and were not previously subjected 
to any neoadjuvant treatment. All female patients (mean age, 59.9 years; range, $38-82$ years) were diagnosed with TNBC, as 0\% ER and PR cell staining was recorded upon immunohistochemical analysis, as well as a HER2 staining score of $0 \%$ upon immunohistochemical analysis or a score of $1+$ and 2+ with no gene amplification, as verified by fluorescence in situ hybridization (6). For all cases, clinicopathological parameters, including age, grading and tumor stage, were recorded according to international guidelines. Data on the follow-up, including the recurrence of the disease, were available for all patients, with the exception of 3 who were lost to follow-up. The study was conducted in accordance with Good Clinical Practice guidelines and the Declaration of Helsinki, and was approved by the Local Ethics Committees of Polyclinic 'G. Martino' (Messina, Italy) and Humanitas Oncology Center (Catania, Italy).

Immunohistochemical methods. All surgical samples were fixed in 10\% neutral formalin for 24-36 $\mathrm{h}$ at room temperature, and then embedded in paraffin at $56^{\circ} \mathrm{C}$. From each tissue block, 4- $\mu \mathrm{m}$ sections were stained with hematoxylin and eosin (H\&E) for microscopic examination. Parallel sections were cut and mounted on silane-coated glasses, then dewaxed in xylene and rehydrated in graded ethanols. Antigen retrieval was performed prior to the addition of the primary antibody lactoferrin [clone 1A1; dilution, 1:75; catalog no., K99172B; Biodesign International, Inc., Saco, ME, USA] by heating slides placed in $0.01 \mathrm{M}$ citrate buffer at $\mathrm{pH} 6.0$ in a microwave oven $(750 \mathrm{~W}$ ) for 3 cycles of $5 \mathrm{~min}$ each.

Immunohistochemical procedures, and positive and negative controls of LF staining were performed as previously described $(18,19)$.

Immunohistochemical quantification. The analysis of immunostained sections was estimated by light microscopy using 20X and 40X objective lenses, and a X10 eyepiece. Two pathologists used a double-headed microscope to perform the assessment of LF-immunostained sections on a consensus basis. The percentage of stained neoplastic cells [area of staining positivity (ASP)] was graded as follows: 0 ) no staining; i) $>0$ to $5 \%$ staining; ii) $>5$ to $50 \%$ staining; and iii) $>50 \%$ staining. In addition, the intensity of staining (IS) (1, weak; 2, moderate; and 3, strong) was also taken into consideration. Successively, a LF intensity distribution (ID) score was calculated for each case by multiplying the ASP and IS values, as previously described $(28,29)$; using this method, only cases showing an ID score of $>2$ were considered as positive for LF.

Moreover, data concerning the Ki-67 labeling index (LI) status were also available and had been evaluated by counting the percentage of positive nuclei per 1,000 malignant cells in up to 10 fields representative of the whole neoplastic portions. The median MIB-1 staining score value $(20 \%)$ was utilized as a cut-off point to determine low and high Ki-67 expression, as described previously (30); this mean value corresponded to the value indicated by the majority of the St. Gallen Breast Cancer Panel (31).

Statistical analysis. The statistical association between LF immunoexpression and the various clinicopathological parameters was investigated using the $\chi^{2}$ test or Fisher's exact test, as appropriate.
Table I. Associations between clinicopathological characteristics and LF expression.

\begin{tabular}{|c|c|c|c|}
\hline \multirow[b]{2}{*}{ Parameter } & \multicolumn{2}{|c|}{ LF immunoexpression } & \multirow[b]{2}{*}{ P-value } \\
\hline & Negative & Positive & \\
\hline Age & & & 1.000 \\
\hline$\leq 70$ years & 26 & 9 & \\
\hline$>70$ years & 25 & 8 & \\
\hline $\mathrm{pT}$ & & & 0.640 \\
\hline 1 & 27 & 10 & \\
\hline 2 & 19 & 4 & \\
\hline 3 & 1 & 1 & \\
\hline 4 & 4 & 2 & \\
\hline \multicolumn{4}{|l|}{$\mathrm{pN}$} \\
\hline No & 30 & 8 & \\
\hline $\mathrm{N}+$ & 21 & 9 & \\
\hline Histological grade & & & 0.410 \\
\hline 2 & 20 & 6 & \\
\hline 3 & 31 & 11 & 1.000 \\
\hline Ki-67 LI & & & $0.040^{\mathrm{a}}$ \\
\hline Low $(\leq 20 \%)$ & 20 & 12 & \\
\hline High $(>20 \%)$ & 31 & 5 & \\
\hline Recurrence & & & $0.010^{\mathrm{a}}$ \\
\hline Absent & 19 & 13 & \\
\hline Present & 29 & 4 & \\
\hline Status & & & $0.020^{\mathrm{a}}$ \\
\hline Alive/SID & 23 & 14 & \\
\hline $\mathrm{SD}$ & 25 & 3 & \\
\hline
\end{tabular}

${ }^{\text {a }}<<0.05$. LF, lactoferrin; SD, succumbed to disease; SID, succumbed independently of disease; LI, labeling index.

Disease-free survival (DFS) and cancer-specific survival (CSS) were assessed by the Kaplan-Meier method, with the date of primary surgery as the entry data. The end point for the DFS analysis was disease progression. CSS was characterized as the length of survival to mortality due to TNBC or to the last follow-up date. Patients who succumbed as a result of diseases independent from TNBC were censored. The Mantel-Cox log-rank test was applied to assess the strength of the association between DFS or CSS and each of the parameters [age, histological grade, pathological tumor (pT) stage, pathological node (pN) stage (6)], Ki-67 LI and LF immunoexpression) as a single variable. Successively, a multivariate analysis (Cox regression model) with stepwise method was utilized to determine the independent effect of each variable on survival.

$\mathrm{P}<0.05$ was considered to indicate a statistically significant difference. Data were analyzed using the SPSS package version 6.1.3 (SPSS, Inc., Chicago, IL, USA).

\section{Results}

The routinely stained H\&E sections exhibited good morphology, confirming the histopathological diagnosis of 
Table II. Associations between LF and recurrence.

\begin{tabular}{|c|c|c|c|c|c|c|c|}
\hline \multirow[b]{2}{*}{ Variables } & \multirow[b]{2}{*}{ Patients, $\mathrm{n}$} & \multirow{2}{*}{$\begin{array}{c}\text { Disease progression, } \\
\mathrm{n}(\%)\end{array}$} & \multirow[b]{2}{*}{ P-value } & \multicolumn{2}{|c|}{ Univariate } & \multicolumn{2}{|c|}{ Multivariate } \\
\hline & & & & HR $(95 \%$ CI $)$ & P-value & HR $(95 \%$ CI $)$ & P-value \\
\hline Age, years & & & 0.460 & & 0.120 & & $0.02^{\mathrm{a}}$ \\
\hline$\leq 70$ & 33 & $15(45)$ & & 1.0 & & 1.0 & \\
\hline$>70$ & 32 & $18(56)$ & & $1.6(0.8-3.0)$ & & $2,3(1.1-4.8)$ & \\
\hline $\mathrm{pT}$ & & & 0.250 & & $0.040^{\mathrm{a}}$ & & $0.001^{\mathrm{a}}$ \\
\hline 1 & 36 & $15(42)$ & & 1.0 & 1.0 & & \\
\hline 2 & 21 & $12(57)$ & & $1.3(0.6-2.8)$ & & 1.0 & \\
\hline 3 & 2 & $1(50)$ & & $1.6(0.1-15.1)$ & & 1.0 & \\
\hline 4 & 6 & $5(83)$ & & $3.8(0.7-18.5)$ & & $5.9(1.9-17.6)$ & \\
\hline $\mathrm{pN}$ & & & 0.800 & & 0.250 & & \\
\hline N0 & 35 & 17 (49) & & 1.0 & & & \\
\hline $\mathrm{N}+$ & 30 & $16(53)$ & & $1.4(0.7-2.9)$ & & NSS & \\
\hline Histological grade & & & 0.310 & & 0.150 & & \\
\hline 2 & 24 & $10(42)$ & & 1.0 & & & \\
\hline 3 & 41 & $23(56)$ & & $1.6(0.8-3.3)$ & & NSS & \\
\hline Ki-67 LI & & & 0.080 & & 0.150 & & $0.007^{\mathrm{a}}$ \\
\hline Low $(\leq 20 \%)$ & 31 & $12(39)$ & & 1.0 & & $0.3(0.1-0.7)$ & \\
\hline High (>20\%) & 34 & $21(62)$ & & $1.6(0.8-3.2)$ & & 1.0 & \\
\hline LF expression & & & $0.010^{\mathrm{a}}$ & & $0.030^{\mathrm{a}}$ & & \\
\hline Absent & 48 & $29(60)$ & & $2.9(1.2-6.2)$ & & & \\
\hline Present & 17 & $4(24)$ & & 1.0 & & NSS & \\
\hline
\end{tabular}

${ }^{\mathrm{a}} \mathrm{P}<0.05$. LI, labeling index; LF, lactoferrin; pT, pathological tumor; $\mathrm{pN}$, pathological node; HR, hazard ratio; CI, confidence interval, NSS, not statistically significant.

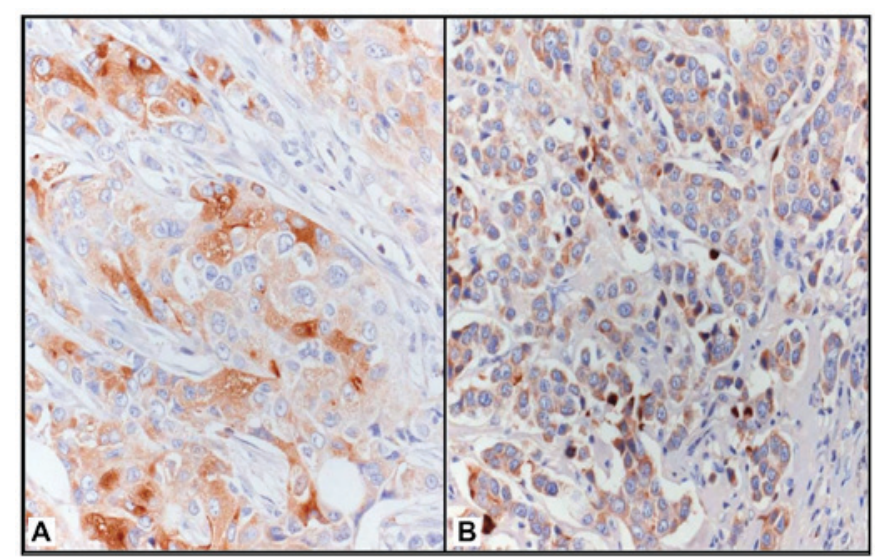

Figure 1. (A) Evident LF immunoreactivity in TNBC, with strongly and slightly positive tumor cells in direct contact (original magnification, $\mathrm{x} 400$ ). (B) Uniform granular cytoplasmic LF immunostaining (original magnification, x320). Immunoperoxidase, with Mayer's hematoxylin counterstain.

ductal invasive breast carcinoma (BC) in all cases. The immunoistochemical confirmed the diagnosis of TNBC.

Clinicopathological and immunohistochemical data for LF for the 65 available TNBC cases analyzed are shown in Table I. The follow-up time ranged from 3 to 112 months (mean, 54.5 months).
LF immunostaining was mainly localized in the cytoplasm of neoplastic elements and occasionally in the nucleus of the same cells; 17 cases $(26.15 \%)$ exhibited an ID score of $>2$ and were therefore considered as positive for LF (Fig. 1). Statistical analyses showed that LF positivity was significantly associated with a low Ki-67 LI $(<20 \%$; P=0.040), the absence of recurrence $(\mathrm{P}=0.010)$ and alive status $(\mathrm{P}=0.020)$.

Univariate analysis showed that a high pT stage $(\mathrm{P}=0.040)$ and the absence of LF immunoexpression $(\mathrm{P}=0.030)$ were significantly associated with shorter DFS times (Table II). Multivariate analysis for DFS demonstrated that patient age, pT stage and Ki-67 LI were independent variables (Table I).

Univariate analysis for CSS showed that an age $>70$ years $(\mathrm{P}=0.007)$ and a high $\mathrm{pT}$ stage $(\mathrm{P}=0.030)$ were significant negative prognostic factors (Table III). The absence of LF immunoexpression was not associated with shorter CSS times, since statistical significance was not reached $(\mathrm{P}=0.060$; Table III). At multivariate analysis, patient age $(\mathrm{P}=0.004)$, pT stage $(\mathrm{P}=0.008)$ and Ki-67 LI $(\mathrm{P}=0.040)$ emerged as independent variables (Table III).

\section{Discussion}

It is well known that lactating breast tissue, as well as ductules and intralobular duct epithelial cells in normal and dysplastic tissue, strongly stain for LF (25); consequently, LF has 
Table III. Associations between LF and survival.

\begin{tabular}{|c|c|c|c|c|c|c|c|}
\hline \multirow[b]{2}{*}{ Variables } & \multirow[b]{2}{*}{ Patients, $\mathrm{n}$} & \multirow{2}{*}{$\begin{array}{l}\text { Succumbed to } \\
\text { disease, } \mathrm{n}(\%)\end{array}$} & \multirow[b]{2}{*}{ P-value } & \multicolumn{2}{|c|}{ Univariate } & \multicolumn{2}{|c|}{ Multivariate } \\
\hline & & & & HR $(95 \%$ CI) & P-value & HR $(95 \% \mathrm{CI})$ & P-value \\
\hline Age, years & & & 0.120 & & $0.007^{\mathrm{a}}$ & & $0.004^{\mathrm{a}}$ \\
\hline$\leq 70$ & 33 & $10(30)$ & & 1.0 & & 1.0 & \\
\hline$>70$ & 32 & $18(56)$ & & $2.6(1.2-5.7)$ & & $3.3(1.4-7.5)$ & \\
\hline $\mathrm{pT}$ & & & 0.070 & & $0.030^{\mathrm{a}}$ & & $0.008^{\mathrm{a}}$ \\
\hline 1 & 36 & $11(31)$ & & 1.0 & 1.0 & & \\
\hline 2 & 21 & $11(52)$ & & $1.7(0.7-3.8)$ & & 1.0 & \\
\hline 3 & 2 & $1(50)$ & & $2.1(0.1-24.3)$ & & 1.0 & \\
\hline 4 & 6 & $5(83)$ & & $4.3(0.8-20.9)$ & & $4.4(1.4-13.3)$ & \\
\hline $\mathrm{pN}$ & & & 0.620 & & 0.340 & & \\
\hline No & 35 & $14(40)$ & & 1.0 & & & \\
\hline $\mathrm{N}+$ & 30 & $14(47)$ & & $1.4(0.6-3.0)$ & & & \\
\hline Histological grade & & & 0.300 & & 0.120 & & \\
\hline 2 & 24 & $8(33)$ & & 1.0 & & & \\
\hline 3 & 41 & $20(49)$ & & $1.8(0.8-3.9)$ & & & \\
\hline Ki-67 LI & & & 0.150 & & 0.610 & & $0.04^{\mathrm{a}}$ \\
\hline Low $(\leq 20 \%)$ & 31 & $12(39)$ & & 1.0 & & $0.3(0.1-0.9)$ & \\
\hline High (>20\%) & 34 & $16(47)$ & & $1.2(0.5-2.5)$ & & 1.0 & \\
\hline LF expression & & & $0.020^{\mathrm{a}}$ & & $0.060^{\mathrm{a}}$ & & \\
\hline Absent & 48 & $25(52)$ & & $2.9(1.2-6.7)$ & & & \\
\hline Present & 17 & $3(18)$ & & 1.0 & & & \\
\hline
\end{tabular}

${ }^{\text {a }}<<0.05$. LI, labeling index; LF, lactoferrin; pT, pathological tumor; pN, pathological node; HR, hazard ratio; CI, confidence interval.

been considered a potential marker for glandular or acinar differentiation, similar to its use in other malignancies $(9,18,22)$. However, in breast cancer, the association between LF expression and clinical parameters is not well defined (24), even if it has been hypothesized that tumors with high LF expression retain a certain degree of physiological control over cell growth, which may explain a good prognosis (25).

In the present TNBC series, an LF immunostaining rate (ID score) of $>2$ was found in $\sim 26.15 \%$ of cases, and was significantly associated with a low Ki-67 LI $(<20 \%)$, the absence of recurrence and an alive status. Therefore, given the aggressive course of TNBC, the presence of LF-immunopositive cases may identify a more indolent subtype of the disease with peculiar clinical characteristics, including less aggressive biological behavior and a more favorable prognosis; by contrast, shorter DFS and CSS times were significantly associated with the absence of LF immunoexpression.

However, a similar capability to select a TNBC subgroup with low biological aggressiveness has been attributed to androgen (AR) expression (6,7); in particular, AR has been shown to be a favorable prognostic factor of DFS and overall survival, with significantly decreased recurrence and mortality risks $(6,7,32)$. Furthermore, in a series of 105 TNBC patients with stage II or III disease treated with neoadjuvant chemotherapy based on docetaxel and doxorubicin, the prognostic and the predictive role of $\mathrm{Ki}-67$ has been analyzed, identifying two distinct subgroups of TNBC with different Ki-67 expression, responses and prognoses (33). In the present study, Ki-67 emerged as an independent variable for DFS and CSS in TNBC, further highlighting its prognostic value. In addition, TNBC LF-positive cases always expressed lower levels of Ki-67, displaying a significant inverse association between Ki-67 LI and LF immunoreactivity, thus representing a further element to assess a favorable group of TNBC characterized by a low risk of recurrence and a better prognosis.

In conclusion, the results of the present study appear to be notable with regard to the field of TNBC, although further validation in large prospective studies is required to enable LF to be a promising biomarker. In fact, together with previous studies, the results of the present study show that the first immunohistochemical application of LF in TNBC appears to favor the selection of patients with a less aggressive behavior, particularly in combination with $\mathrm{Ki}-67$ status and AR expression. However, additional investigations are also required with regard to the potential of LF in cancer treatment, due to its nutraceutical function and its ability to potentiate chemotherapy.

\section{References}

1. Prat A, Parker JS, Karginova O, Fan C, Livasy C, Herschkowitz JI, $\mathrm{He} \mathrm{X}$ and Perou CM: Phenotypic and molecular characterization of the claudin-low intrinsic subtype of breast cancer. Breast Cancer Res 12: R68, 2010.

2. Perou CM: Molecular stratification of triple-negative breast cancers. Oncologist 16 (Suppl 1): S61-S70, 2011. 
3. Lehmann BD, Bauer JA, Chen X, Sanders ME, Chakravarthy AB Shyr Y and Pietenpol JA: Identification of human triple-negative breast cancer subtypes and preclinical models for selection of targeted therapies. J Clin Invest 121: 2750-2767, 2011.

4. Lehmann BD, Bauer JA, Schafer JM, Pendleton CS, Tang L, Johnson KC, Chen X, Balko JM, Gómez H, Arteaga CL, et al: PIK3CA mutations in androgen receptor-positive triple negative breast cancer confer sensitivity to the combination of PI3K and androgen receptor inhibitors. Breast Cancer Res 16: 406, 2014.

5. Kashiwagi S, Yashiro M, Takashima T, Nomura S, Noda S, Kawajiri H, Ishikawa T, Wakasa K and Hirakawa K: Significance of E-cadherin expression in triple-negative breast cancer. Br J Cancer 103: 249-255, 2010.

6. Ricciardi GR, Adamo B, Ieni A, Licata L, Cardia R, Ferraro G, Franchina T, Tuccari G and Adamo V: Correction: Androgen receptor (AR), E-Cadherin, and Ki-67 as emerging targets and novel prognostic markers in triple-negative breast cancer (TNBC) patients. PLoS One 10: e0132647, 2015

7. Safarpour D and Tavassoli FA: A targetable androgen receptor-positive breast cancer subtype hidden among the triple-negative cancers. Arch Pathol Lab Med 139: 612-617, 2015.

8. Abd-Elazeem MA and Abd-Elazeem MA: Claudin 4 expression in triple-negative breast cancer: Correlation with androgen receptors and Ki-67 expression. Ann Diagn Pathol 19: 37-42, 2015.

9. Caselitz J, Jaup T and Seifert G: Lactoferrin and lysozyme in carcinomas of the parotid gland. A comparative immunocytochemical study with the occurrence in normal and inflamed tissue. Virchows Arch A Pathol Anat Histol 394: 61-73, 1981.

10. Tuccari G and Barresi G: Immunohistochemical demonstration of lactoferrin in follicular adenomas and thyroid carcinomas. Virchows Arch A Pathol Anat Histopathol 406: 67-74, 1985.

11. Cabaret V, Vilain MO, Delobelle-Deroide A and Vanseymortier L: Immunohistochemical demonstration of ceruloplasmin and lactoferrin in a series of 59 thyroid tumors. Ann Pathol 12: 347-352, 1992 (In French).

12. Tuccari G, Giuffrè G, Crisafulli C and Barresi G: Immunohistochemical detection of lactoferrin in human astrocytomas and multiforme glioblastomas. Eur J Histochem 43: 317-322, 1999.

13. Zhou Y, Zeng Z, Zhang W, Xiong W, Wu M, Tan Y, Yi W, Xiao L, Li X, Huang C, et al: Lactotransferrin: A candidate tumor suppressor-Deficient expression in human nasopharyngeal carcinoma and inhibition of NPC cell proliferation by modulating the mitogen-activated protein kinase pathway. Int J Cancer 123 2065-2072, 2008.

14. Tuccari G, Barresi G, Arena F and Inferrera C: Immunocytochemical detection of lactoferrin in human gastric carcinomas and adenomas. Arch Pathol Lab Med 113: 912-915, 1989.

15. Walmer DK, Padin CJ, Wrona MA, Healy BE, Bentley RC, Tsao MS, Kohler MF, McLachlan JA and Gray KD: Malignant transformation of the human endometrium is associated with overexpression of lactoferrin messenger RNA and protein. Cancer Res 55: 1168-1175, 1995.

16. Farley J, Loup D, Nelson M, Mitchell A, Esplund G, Macri C, Harrison $\mathrm{C}$ and Gray K: Neoplastic transformation of the endocervix associated with downregulation of lactoferrin expression. Mol Carcinog 20: 240-250, 1997.

17. Giuffrè G, Arena F, Scarfì R, Simone A, Todaro P and Tuccari G: Lactoferrin immunoexpression in endometrial carcinomas: Relationships with sex steroid hormone receptors (ER and PR), proliferation indices (Ki-67 and AgNOR) and survival. Oncol Rep 16: 257-263, 2006.
18. Giuffrè G, Barresi V, Skliros C, Barresi G and Tuccari G: Immunoexpression of lactoferrin in human sporadic renal cell carcinomas. Oncol Rep 17: 1021-1026, 2007.

19. Tuccari G, Giuffrè G, Scarfì R, Simone A, Todaro P and Barresi G: Immunolocalization of lactoferrin in surgically resected pigmented skin lesions. Eur J Histochem 49: 33-38, 2005.

20. Ieni A, Barresi V, Grosso M, Rosa MA and Tuccari G: Immunolocalization of lactoferrin in cartilage-forming neoplasms. J Orthop Sci 14: 732-737, 2009.

21. Ieni A, Barresi V, Grosso M, Rosa MA and Tuccari G: Lactoferrin immuno-expression in human normal and neoplastic bone tissue. J Bone Miner Metab 27: 364-371, 2009.

22. Ieni A, Barresi V, Branca G, Giuffrè G, Rosa MA and Tuccari G: Immunoexpression of lactoferrin in bone metastases and corresponding primary carcinomas. Oncol Lett 5: 1536-1540, 2013.

23. Charpin C, Lachard A, Pourreau-Schneider N, Jacquemier J, Lavaut MN, Andonian C, Martin PM and Toga M: Localization of lactoferrin and nonspecific cross-reacting antigen in human breast carcinomas. An immunohistochemical study using the avidin-biotinperoxidase complex method. Cancer 55: 2612-2617, 1985

24. Ha NH, Nair VS, Reddy DN, Mudvari P, Ohshiro K, Ghanta KS, Pakala SB, Li DQ, Costa L, Lipton A, et al: Lactoferrin endothelin-1 axis contributes to the development and invasiveness of triple-negative breast cancer phenotypes. Cancer Res 71: 7259-7269, 2011.

25. Tuccari G and Barresi G: Lactoferrin in human tumours: Immunohistochemical investigations during more than 25 years. Biometals 24: 775-784, 2011.

26. Penco S, Caligo MA, Cipollini G, Bevilacqua G and Garré C: Lactoferrin expression in human breast cancer. Cancer Biochem Biophys 17: 163-178, 1999.

27. Benaïssa M, Peyrat JP, Hornez L, Mariller C, Mazurier J and Pierce A: Expression and prognostic value of lactoferrin mRNA isoforms in human breast cancer. Int J Cancer 114: 299-306, 2005.

28. Ieni A and Tuccari G: Comments on the 'Prognostic impact and clinicopathological correlation of CD133 and ALDH1 expression in invasive breast cancer'. J Breast Cancer 19: 96-98, 2016.

29. Ieni A, Barresi V, Branca G, Giuffrè G, Rosa MA and Tuccari G: Immunohistochemical Investigation of lactoferrin in human bone primary and metastatic tumours. Int J Lab Med Res 1: IJLMR-105.

30. Ieni A, Giuffrè G, Lanzafame S, Nuciforo G, Curduman M, Villari L, Roz E, Certo G, Cabibi D, Salomone E, et al: Morphological and biomolecular characteristics of subcentimetric invasive breast carcinomas in Sicily: A multicentre retrospective study in relation to trastuzumab treatment. Oncol Lett 3: 141-146, 2012.

31. Goldhirsch A, Winer EP, Coates AS, Gelber RD, PiccartGebhart M, Thürlimann B and Senn HJ; Panel members: Personalizing the treatment of women with early breast cancer: Highlights of the St Gallen international expert consensus on the primary therapy of early breast cancer 2013. Ann Oncol 24: 2206-2223, 2013.

32. Ieni A, Barresi V, Ricciardi GR, Adamo B, Adamo V and Tuccari G: Prognostic value of androgen receptor expression in triple negative breast carcinomas: Personal experience and comments on a review about 'Triple-negative breast cancer: Treatment challenges and solutions' by Collignon et al. Breast Cancer (Dove Med Press) 8: 157-159, 2016.

33. Rakha EA, El-Sayed ME, Green AR, Lee AH, Robertson JF and Ellis IO: Prognostic markers in triple-negative breast cancer. Cancer 109: 25-32, 2007. 